Historic, archived document

Do not assume content reflects current scientific knowledge, policies, or practices. 

Cleaning and tinning the steel and copper.-It is of first importance to have the capping steel and tipping copper in good condition. These may need to be rubbed with coarse sandpaper or on a soft brick to smooth them, or the steel may have to be filed to take the rust off. In the latter case care must be taken to keep the edge of the steel true. Both the capping steel and tipping copper must be kept tinned or coated with solder to make the solder flow evenly when sealing. Have ready in a can a handful of sal ammoniac mixed with a few pieces of solder. Heat the already smoothed capping steel or tipping copper until almost red hot, dip into the flux, then into the sal ammoniac and solder, turning it about and rubbing until bright and well coated with solder. Then dip into the flux again.

Preparation of vegetables.-In securing a fine quality, much depends upon having the vegetables or fruit absolutely fresh, crisp, and clean, and kept cool. All surroundings and utensils should be spotlessly clean, and all operations from beginning to end of any lot of canning should be carried on as rapidly as possible. A good slogan is "One hour from the field to the can." First have cans and lids thoroughly washed and scalded. Sort and grade the fruit, discarding all defective ones, and use together those of same size. Use only uniformly well ripened products. Only young, tender, quickly grown vegetables retain their flavor when canned.

STFPS TAKEN IN CANNING IN TIN.

1. Sorting and grading fruit or vegetables, washing, peeling, etc.

2. Scalding, peeling, and coring (for tomatoes).-Put into trays and lower into boiling water for one minute. Remove at once to prevent cooking. Plunge into cold water to make the fruit firm, and peel promptly. In tomato peeling use a slender pointed knife to cut out the core and be careful not to cut into the seed cells. Keep the tomatoes whole when possible.

3. Blanching consists of plunging the vegetable or fruit into boiling water for a short time. Use a wire basket or cheese cloth square for this. The blanch gives a more thorough cleaning, removes the strong odor and flavor from certain kinds of vegetables, improves the texture, and insures a clearer liquor. It also shrinks the fruit or vegetable and makes it more flexible. A full pack is then more easily made. The time required for blanching varies with the state of maturity. Beans should be blanched until tender enough to bend without breaking. Peaches will pack better if quickly blanched by lowering for 15 seconds into water below boiling (about $180^{\circ} \mathrm{F}$.). The same blanch will make the hard varieties of pears pack better and give them a more transparent appearance; and used for cherries will prevent splitting and cracking. Spraying fruit with cold water after blanching will make it firmer. Frequently it is well to put the 
vegotable into cold water for an instant after blanching to make more crisp. In blanching asparagus, tio a few stalks in each bundle, lower the bundle into water, tips up, blanching the lower ends one or two minutes before immersing the tips. Blanch the tips only two or three minutes.

4. Packing (see tablo for size of cans to use for different vegetables). - The Federal laws require the cans to be filled as full of food as is practicable for processing and to contain only onough liquor to fill the spaces and cover tho contents. Weigh a sufficiont number of cans before and after filling to obtain an accurate idea of arerage net weight. On account of expansion in procossing, corn can be packed less full than other vegetables. Theso instructions do not cover the canning of corn for market. Mark the cans with a pencil or knife to show contents. Plan in advanco and work rapidly. Lot ono person do the packing and another attend to tho weighing. Do not allow filled cans to stand before adding liquor and exhausting. To do so will injure the product.

5. Adding brine, sirup, or water. - After adding to within $\frac{1}{4}$ inch of top, shake the can gently to displace all air within it. Now clean and wipe the groove around the opening. Slip on tho cap and weigh before sealing to be sure of having the required weight.

6. Fluxing and capping.-Apply tho flux carefully around the groove, making sure that none of it enters the can. Use a small brush or cord, or little mop made by tying a piece of clean white cloth around the end of a small stick. The flux is used to make the solder adhere to the tin. Apply the clean, hot capping steel, holding the cap in place with the center rod; while you lower the steel, turn it steadily until the solder flows. Hold the rod firmly and lift the steel with a sudden twist to swing the melted solder around the groove evenly.

7. Exhausting.-Place tho cans in trays and lower into boiling water to within 1 inch of the top to drive the air out of the cans. Let them stay the shortest possible time necessary to drive out the air. Ordinarily three minutes is enough, and the tomperature need not again reach boiling before cans are taken out. Frequently, exhausting is done at $180^{\circ} \mathrm{F}$. Exhausting is necessary. If omitted, the air left in the can expands, causing it to bulge. The can may not resume normal shape again, or if it does and is exposed to a warmer temperature it may again expand, giving tho appearance of a "swell." This will not only prevent sale of that can, but may also cut off future orders. Furthermore, the presence of air may cause the tin to dissolve more readily and enter into the food. Exhausting is required where the 4-H Brand label is used.

8. Tipping.-Close the small hole in top of the can immediately after exhausting. Apply flux as for capping, and use a little wire 
solder to close the hole. Hold the solder with left hand near the hole and barely touch the hot copper to it, so that only a bead will drop and cover the hole. This makes a neat tip.

9. Processing.-Boil the cans which have been exhausted and tipped to sterilize the contents. Have the water boiling vigorously when the cans go in. Lower cans slowly under the water and look out for any showers of bubbles from a can. These show that it leaks at the point from which the bubbles come and must be taken out and resoldered. Begin counting time when the water first boils after immersing the cans. Keep it boiling constantly. In intermittent processing the vegetable is processed for one hour on each of three successive days. The time is sometimes reduced to two days with very young string beans and some other more easily sterilized regetables. It is not possible to state the shortest time which may bo used safely because of the varying conditions.

10. Cooling.-Cool all canned products as quickly as possible to stop the cooking, which breaks down the fruit and injures the flavor and color. Plunge the cans into very cold water immediately, especially when processing intermittently. Never stack cans close together until entirely cold.

11. Labeling.-After 8 to 10 days, or immediately before selling, label all cans. Place the sealed end down, so that the opposite end will appear at the top when placed on the shelf. Use a rather dry paste, and put it only on the end of the label, so that no paste will touch the tin. If paste touches the can, it may cause rust. Where a damp climate causes cans to rust easily, the outside of the can may be lacquered before being labeled. Club members may use the 4-H Brand label only on first-class goods. They must put net weight in pounds and ounces and packer's name and address on each can. Every girl thus guarantees her own goods.

\section{BRINING AND SEASONING.}

Brine, sirup, or water are added immediately after packing to such fruits and vegetables as need to be surrounded by a liquid either for proper preparation or for purpose of sterilization. No more liquor is allowed than is actually necessary to cover the contents after as full a pack as possible is made. All 4-H Brand tomatoes have a mixture of sugar and salt added. Mix this in the proportion of one-third salt and two-thirds sugar and put two level teaspoonfuls in each No. 3 can of tomatoes and one teaspoonful in each No. 2 can. Use this for peas, lima beans, and corn. It is required that all products to be sold be packed with the sirup or brine indicated, so as to come up to the standard. The flavor of such products is much superior to those without sugar or salt. In canning tomatoes, no addition of tomato juice in excess of the amount present in the tomatoes canned is allowed. Any water is considered 
an adulteration. In canning tomatoes in glass for exhibits and home use, when it is desirable to keop the tomatoes whole, they may be packed carefully and a thick liquor poured over them. 'This may be obtained by cooking smaller or broken tomatoes and putting through a sieve.

Brine for beans, okra, cauliflower, etc., should contain $2 \frac{1}{2}$ ounces salt to a gallon of water. For asparagus a heavier brine, 4 ounces to a gallon of water, is needed.

\section{STANDARDS FOR 4-H BRAND CANNED VEGETABIES.}

Tomatoes.-Cans to contain not less than 2 pounds 1 ounce tomatoes in No. 3 and not loss than 1 pound 4 ounces tomatoes in No. 2. To bo filled with sound ripo fruit, carefully peeled and cored; tomatoes to be whole or in large pieces, firm, uniformly red, and of good flavor.

Tomatoes and green pepper.-Cans to contain not less than 2 pounds packed in No. 3 cans. For this pack add one medium-size green sweet pepper, after removing the stem and seeds, to each can of tomatoes.

String beans.- Net weight in No. 3 can beforo liquor is added at least 1 pound 8 ounces, brine 8 to 10 ounces. Net weight No. 2, 13 ounces beans and about 8 ounces liquor. Beans to be tender, green, uniform in size, well strung, and of good flavor. The net weight which appears on label should be for No. 3, 2 pounds, for No. 2, 1 pound 5 ounces.

Peas.-No. 2 cans to have at least $13 \frac{1}{2}$ ounces net weight of peas and about $8 \frac{1}{2}$ ounces liquor-peas to be fairly unifor'm in size, tender, whole, and of good flavor; liquor clear. Net weight appearing on label should be for No. 2 cans 1 pound 8 ounces.

Baby beets. -To be packed in No. 2 lacquered tins, about 30 baby beets to each can, maximum size $1 \frac{1}{2}$ inches in diameter and average size 1 inch in diameter. No. 2 can to have at least 16 ounces wholo beets and 4 ounces liquid. Net weight which appears on label should be for No. 2 can 1 pound 4 ounces.

Okra.-Net weight of contents in No. 3 can should appear on label, 2 pounds. Only young, tender okra should be packed, and it is best to simply remove the cap without cutting into the seed pod and pack it whole. Brine is added as explained in the table.

Peppers.-No. 2 cans to contain between 8 and 10 wholo peppers. Flat No. 1 cans to contain 4 or 5 whole peppers, and net weight of contents appearing on the label should be for No. 2 can not less than 1 pound, or flat No. 1 can not less than 8 ounces.

Soup mixture.-This should consist of a mixture which is made in the proportion of one-half tomato pulp, one-fourth corn or tiny lima beans, and one-fourth okra with seasoning added. One slice of onion 2 inches in diameter should be added to each No. 2 can. The toma- 
toes should be heated, rubbed through a sieve and cooked down to about the consistency of ketchup before measuring; then the corn, okra, onion, and seasoning should be added and cooked until the corn and okra are about three-fourths done. Then pack into cans and follow directions as given in the table on page 8 . Net weight of contents appearing on label of No. 2 can should be 1 pound $4 \frac{1}{2}$ ounces.

\section{PREPARATIONS FOR CANNING IN GLASS.}

Jars. - The glass-top jar with wire clamp is the best type of jar for use in intermittent processing. If products are to be sold, a gool commercial jar is necessary. Commercial jars when purchased in gross quantities are cheaper than household jars and can be chosen in appropriate size for each product. A 10 or 12 ounce jar with glass top and screw rim can be effectively used for preserves, jams, pickles, etc. Another good type of commercial jar is one with hermetic cap and can be had in different sizes for various products. A 4-ounce size is suitable for individual service, a 10-ounce size for general use.

Assemble all supplies and utensils such as jars, new rubbers and lids, wooden spoons, paddle, one-half pint measuring cup, measuring spoons, paring knives, sugar, salt, soda, etc., in a clean convenient place in which to work.

\section{STEPS TO BE TAKEN IN CANNING IN GLASS.}

The steps 1, 2, and 3, under "Canning in tin," are also to be followed when packing in glass. Sterilize jars by placing them in a vessel, side down, covering with eold water, bringing to a boil and boiling for 15 minutes.

4. Packing.-After selecting fruit or vegetables for uniformity in size and quality (see score) it should be arranged with reference to symmetry and the best use of the space within the jar. In placing the fruit or vegetable in a jar, a thin, slender, flexible paddle made out of cane is useful. This paddle is also used to take out the bubbles of air by running it down the side of the jar to touch these bubbles after the liquor has been added to the pack.

5. Adjusting the cap.-Before placing the cap be sure that the rubber is flattened in its groove, without the presence of any seed or particle of the fruit. When a screw-top jar is used, screw the cap evenly about halfway. When a glass-top jar with wire clamp is used, place the lid on evenly and raise both clamps up, the upper one fastened to hold the lid in place. With an hermetic jar, fasten the cap on the jar evenly with the clamp. This type of jar is self-sealing as it cools.

6. Processing.-Place the jars in a water bath on a rack (a wooden one is good) to avoid breaking. Have the water the same temperature as the contents, letting it come to within 2 inches of the tops of jars. Have a tight cover for the vessel to keep in the steam. Do not 
count timo until the water begins to boil; keep it boiling steadily for the time required. Seal the jars air-tight promptly at end of processing and remove them from the bath, being caroful not to allow a cold draft to strike them. In intermittent processing, raise the clamp of each jar at the beginning of each processing to allow for expansion. Seal at close of each processing. The hermetic jar is not a suitablo one for intermittent processing.

7. Store products in a cool, dry, dark place.

8. Labeling.-Before labeling, wash and polish each jar. Place the label on the plain side of the jar midway between the seams onefourth inch from the lower edge. On every label must appear the name of the contents, name and address of the packer, and net weight in pounds and ounces.

Score for judging the quality of canned fruits and vegetables.

\begin{tabular}{|c|c|c|}
\hline 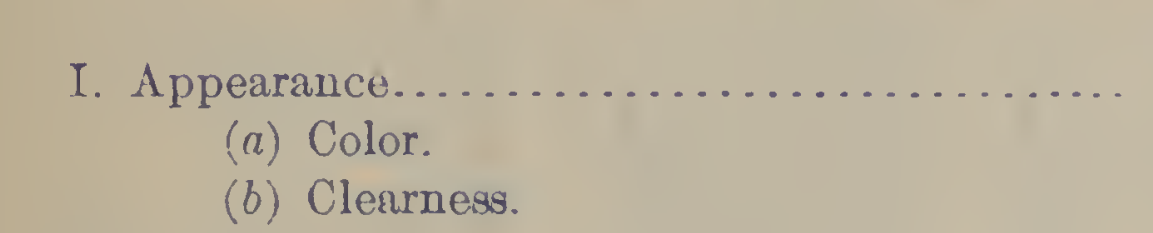 & $\begin{array}{c}\text { Soore of } 100 . \\
2 j\end{array}$ & $\begin{array}{c}\text { Score of } 30 . \\
7 !\end{array}$ \\
\hline 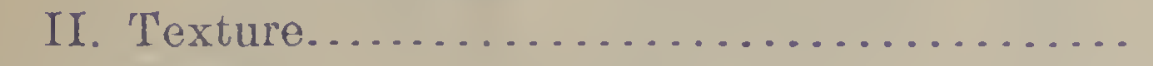 & 10 & 3 \\
\hline III. Flavor........... & 20 & 6 \\
\hline $\begin{array}{l}\text { IV. Uniformity........................ } \\
\text { (a) Ripeness. } \\
\text { (b) Appropriate size. }\end{array}$ & 15 & $4 \frac{1}{2}$ \\
\hline 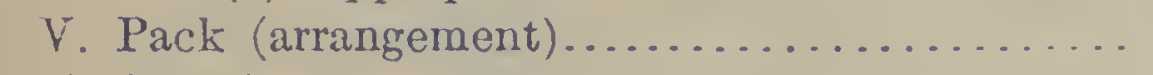 & 15 & $4 \frac{1}{2}$ \\
\hline $\begin{array}{l}\text { VI. Container.................................. } \\
\text { (a) Appropriate package. } \\
\text { (b) Label. } \\
\text { (c) Neatnes.. }\end{array}$ & 15 & $4 \frac{1}{3}$ \\
\hline
\end{tabular}

STANDARDS FOR 4-H BRAND CANNED FRUTTS.

Figs.-The net weight contents of a No. 2 enamel-lined can of figs should, as shown on the label, be not less than 1 pound 6 ounces. Figs should remain whole and a No. 2 can should contain about 30 to 35 whole figs.

Peaches. - A No. 3 can should have at least 1 pound 5 ounces solids and 11 ounces liquid, should contain between 10 and 12 halves of peaches, and the net weight of contents appearing on label should be not less than 2 pounds.

Pears. - The net weight in a No. 3 can should be not less than 2 pounds, having 11 ounces liquid, 1 pound 5 ounces solids, and botwoen 12 and 14 halves.

Berries. - The net weight of a No. 3 can of blackberries or raspberries should be 2 pounds; of a No. 2 can, 1 pound 6 ounces, whole berries weighing about one-half of total in each case. The berries should be large, whole, and of good color and flavor. The sirup used in packing must be made out of strained berry juice and sugar, with no water added. Enamel-lined cans should always be used. 


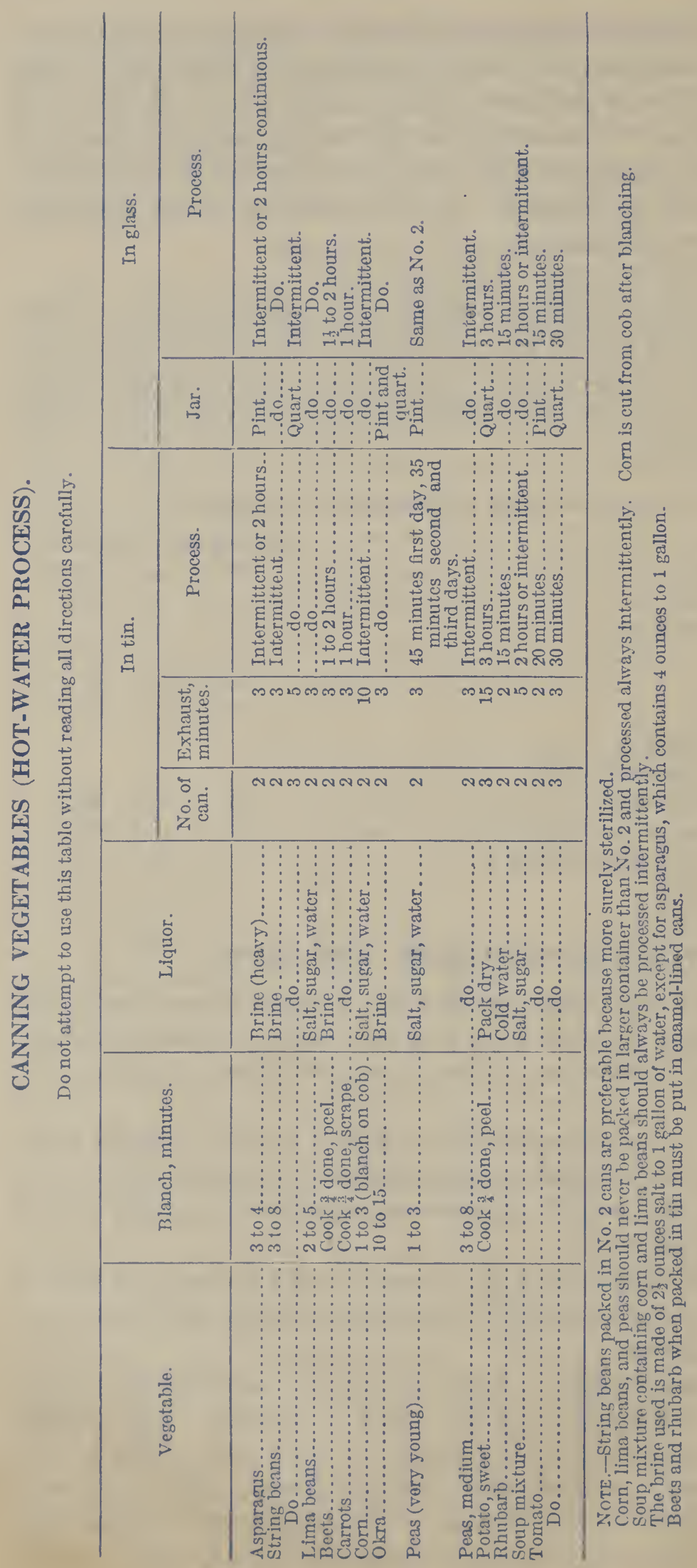


CANNING, PRESERTING, PICKLING.

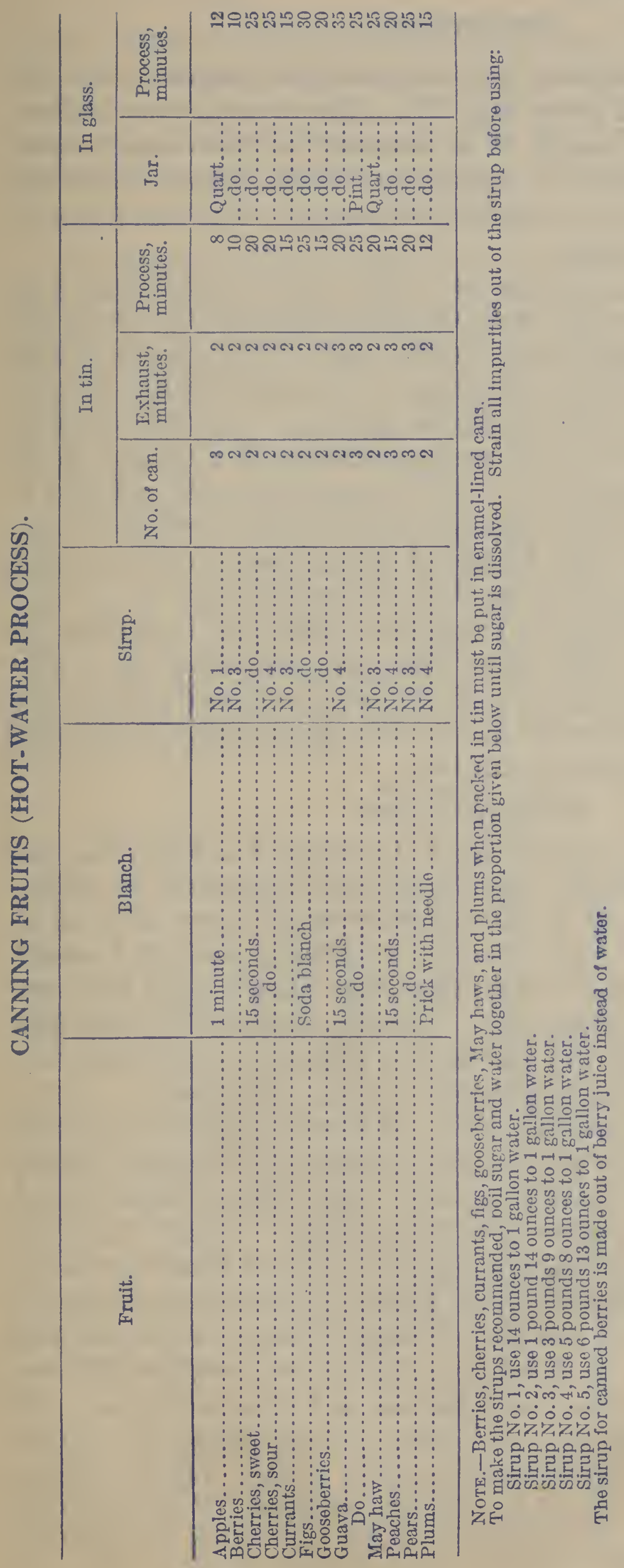




\section{PRESERVTNG.}

These recipes are prepared for advanced club members who are ready to begin work in preserving. In order to secure the uniform products required for market, it is necessary to have some special requipment. Good enamel or aluminum vessels, scales, measuring cups, wooden spoons and paddles, thermometers, and saccharometer (see letter 853) are needed.

In making preserves, the object is to have the fruit permeated with sirup. Care must be taken to do this gradually so as to prevent the shrinking and toughening which results when fruit is placed at once in very dense sirup. It is also important not to pack the finished preserves in sirup heavy enough to crystallize later. To insure accurate and uniform results, test with a saccharometer the density of all sirups used in packing preserves. A 250-centimeter glass cylinder or other tall slender vessel is needed to hold the sirup in which the saccharometer is floated. The degrees of density used in these recipes are those.indicated by Balling or Brix saccharometers.

Process preserves or jam in 12-ounce or pint jars, 20 minutes at $180^{\circ} \mathrm{F}$. (simmering). When jars with glass top and screw oap or wire clamp (lightning seal) are used, tighten cap immodiately at end of processing. When hermetic jar's are used, leave clamp on cap until jar is entirely cold. Measurements level.

\section{PRESERVED RERRIES.}

Practically the same methods are to be followed in preserving and making jams of all berries. Berries should bo gathered in shallow trays or baskets and not in deep ressels which allow them to be bruised and crushed. They should bo uniform, ripe, and sound. Select only large, firm berries for preserving; those for jam may contain the smaller and broken ones. All berries should be carefully sorted and lightly washed by placing in a colander and pouring water over them rather than putting them into a pan of water.

To retain the best possible color and flavor, sirup for preserved berries should be made of a berry juice obtained by crushing, heating and straining the softer, broken berries. Add 1 pint of sugar to each pint of berry juice and allow to boil 10 minutes. Weigh the shoice perfect berries after removing tho caps or stems and allow 1 pound of sugar extra for ench pound of whole berries. Add the extra sugar to tho sirup, bring to a boil and skim. Removo from the fire and cool surup before dropping tho berries into it to prevent shriveling and toughening the fruit. Place over the fire and bring slowly to a boil and simmer until the berries are heated through, being very careful not to overcook; the berries should remain whole. Lift the berries from the sirup and place carefully in to shallow pans. Pour sirup over them and allow to stand over night. Pack cold, filling the jar with 
berries before pouring the sirup over them. Cap, process, and seal. The prescrves may be packed hot, after removing from the fire, capped and processed immediately. The sirup in which berry preserves are packed should have density of $50^{\circ}$ to $55^{\circ}$ and will often need to be boiled down to this density after removing berries.

JAM.

In selecting berries for jam, the ripe broken ones suggested above will give fine color and flavor, but at the same time there should always be about one-half the quantity which are slightly underripe. This is necessary to give a jelly-like consistency to the product. Cooking in small quantities also helps to retain color and flavor. Weigh the berries and allow three-fourths pound of sugar to each pound of fruit. Rapid cooking with constant care is essential.

In stirring jam use a wooden spoon or paddle, moving it across the center of the ressel first one way and then the opposite and next around the pan, gently moving the mixture from the bottom of the pan, being careful not to stir rapidly or beat. Cook the jam to $220^{\circ} \mathrm{F}$. When finished it will give the same test as required from finished jelly; that is, when a little is held a moment, cooled in a spoon - and allowed to drop from the side of the spoon it will not pour but will fall in a sheet or flake.

PRESER VED FIGS.

6 çuarts figs.

2 quarts sugar.

3 quarts water.

Select firm sound fruit, discard all orerripe or broken figs. Sprinkle 1 cup of soda over the selected figs and cover with about 6 quarts of boiling water. Allow to stand 15 minutes, drain off this soda solution and rinse the figs well through two baths of clear cold water. Let the figs drain while sirup is prepared. Mix sugar and water, boil $10 \mathrm{~min}-$ utes and skim. Add well-drained figs gradually so as not to cool the sirup. Cook rapidly until figs are clear and tender (about two hours). When the figs are transparent, lift them out carefully and place into shallow pans. If the sirup is not heary enough (about $50^{\circ}$ ) continue boiling until it reaches this density, then pour it over the figs, being careful to see that the fiuit is entirely covered. Let stand over night. Next morning pack the figs cold into sterilized jars, having stems all the same length and placing the figs so that all stems will be upward. Fill each jar to overflowing with the sirup testing $55^{\circ}$. Cap, clamp, process, and seal immediately.

\section{FIG MARMALADE.}

Select very ripe figs, remove all stems, treat them with scalding soda solution, and rinse thoroughly as in preserving. Cook in quantities not larger than 3 pounds at one time. Allow $1 \frac{1}{2}$ pounds sugar to each 3 pounds of figs. Add barely enough water to start the 
cooking (about one-half oup), crush the figs, heat to boiling, and add the sugar. Cook rapidly to $220^{\circ} \mathrm{F}$., following instructions given under berry jam. Pack and process liko preservos.

\section{PRESERVIDD WATERMELON RIND.}

Cut 1 pound rind into 1 -inch squares. Remove peel and all piuk part. Soak over night in limewater (1 ounce lime to 2 quarts water). The following morning let stand for 2 hours in clear water. Drain well, then drop into boiling water and boil rapidly for 10 minutes. Drain again and add gradually to the sirup (made by boiling together 3 cups sugar, 3 pints water). Add to this tho juice of one-half lemon and three extra slices of lemon. Cook until the melon is tender and transparent. Allow to stand until cold, arrange the pieces attractively in the jars, garnishing with slices of lemon. Corer with the sirup testing $50^{\circ}$ to $55^{\circ}$. Process, and seal.

\section{GINGERED WATERMELON RIND.}

Follow the same method as for preserves until after rind has been freshened in cold water. Then drain woll and boil rapidly for 15 minutes in strong ginger tea (1 ounce ginger to 1 quart water). Finish cooking in a $30^{\circ}$ sirup made by using 1 pint strained ginger tea with 1 quart water and $1 \frac{1}{2}$ pounds sugar. Cook rapidly until terider and transparent (about 2 hours). After rind has boiled for one-half hour, add one-half lemon, cut into thin slices. Pack and process like preserres.

\section{PFACH MARMALADE.}

\begin{tabular}{l|l}
21 pounds peaches cut into small & 1 inch ginger root. \\
pieces. & $\frac{1}{2}$ cup peach juice. \\
1 pound sugar. & $\frac{1}{2}$ teaspoon whole cloves. \\
6 whole allspice. & 1 teaspoon cinnamon bark. \\
1 cracked peach seed. & 1 teaspoon sprig mace.
\end{tabular}

(Tie spices in cheesecloth bag.)

Cook all together until thick as marmalade and clear (to $220^{\circ} \mathrm{F}$.). Pack hot in hot jars and soal at once. If this is done quickly, haring overything very hot, a good seal should result. Howorer, when packing for market, it is far safer to process this jam both to insure sterilization and a tight seal.

\section{GINGEIR PEARS.}

Use pears not quite ripe, peel, core, and cut into thin slices. To 8 pounds of pears, allow 8 pounds sugar, 1 cup of water, juico of 4 lemons. Cut tho lomon rinds into thin strips and add them. Also add $\frac{1}{8}$ pound of ginger root cut into pieces. Simmor until thick as marmalade. Pack, like peach jam. 


\section{PICKLING.}

These recipes have been prepared for uniform 4-H Brand pickles and ketchup. Brine in which vegetables stand for a brief time is about 45 per cent (1 cup salt to 1 gallon water). If vegetables are to be brined for several months it is necessary to use a salt per cent scale (see letter 853) and to secure further instructions.

\section{TOMATO KETCHUP.}

Select red ripe tomatoes. The extra juice, small and broken fruit, which will not do for canning, may be used, if they are sound and red. Any green or yellowish parts of fruit will make a ketchup inferior in flavor and color, and not good for market. Use whole spices tied loosely in a bag while cooking and remove before bottling to prevent darkening the product caused by ground spices. This does not apply to red pepper, which helps to give a bright red color. The pulp of sweet Spanish pepper or the ground Hungarian paprica may also be used to give color and flavor. Remove seeds from sweet red pepper, chop and add 1 cup of this pepper and 2 medium-size onions to 1 gallon tomatoes before cooking.

Cook the tomatoes thoroughly, put through a colander or sieve, saving all pulp, and measure. For every gallon of pulp use the following:

2 tablespoons salt.

4 tablespoons sugar.

1 tablespoon mustard (powdered).

1 pint good vinegar.

1 level tablespoon each of whole allspice, cloves, cinnamon, and pepper.

2 small red peppers sliced and seed removed.

After putting tomatoes through a colander add ground spices and spice bag, and cook for $1 \frac{1}{2}$ hours, or until nearly thick enough, then add vinegar and cook until thick. Rapid cooking (being careful not to scorch the ketchup) will give a better color than slow cooking. The finished product should be a fine bright red.

Pour the ketchup at once into hot sterilized bottles. If any quantity is made for sale, set the hot bottles at once in a vessel of hot water, having a false bottom in it to prevent breakage, put the cork stoppers in loosely and process at boiling point for 30 minutes. Drive the corks in tightly and when cool dip mouth of bottle into melted paraffin, or cover stopper with sealing wax. 
MUSTARD P'ICKLE.

VEG ETABLES.

I) RYASING .

1 pint whole small cucumbers.

1 pint sliced cucumbers

1 pint small wholo onions.

I cup beans.

3 groen sweet peppers.

3 red sweet peppers.

1 pint green fig tomatoes, or 1 pint cauliflower.

1 quart vinegar.

4 tablespoons flour.

1 cup sugar.

3 tablespoons powdered mustard.

紊 tablespoon turmeric.

1 tablespoon celery seed.

Cut all vegetables bofore measuring-tomatoes into halvos, cucumbers into slices, string boans into $1 \frac{1}{2}$-inch longths, diagonally or on the bias, and chop peppers. All vegotables should bo tender, and the whole cucumbers not longer than $2 \frac{1}{2}$ inchos.

Put all vegetables into brine over night, thon froshen in cloar water for 2 hours. Lot those vogetables stand in liquor of one-half vinogar and one-half water for 15 minutes, then scald in same liquor.

To mako mustard dressing, rub all the dry ingredients together until smooth, then add the hot vinegar slowly, stirring to make smooth pasto. Cook over pan of water, stirring carefully, until the sauco thickens. Then drain tho vegetables thoroughly and pour tho mustard dressing ovor thom whilo hot. Mix well and pack in sterilized jars. Process 10 -ounce jars for 20 minutes at $180^{\circ}$ F. (simmering).

\section{SPICED CUCUMBEIR SALAD.}

VEGETABLES.
5 pounds sliced cucumbers (about
2 dozen).
$\frac{1}{2}$ cup chopped oniou.
2 cups cliopped sweet red peppor.
1 cup chopped sweet green pepper.

SPICED VINEGAR.

1 quart vinegar.

$\frac{1}{2}$ cup sugar.

1 tablespoon each salt, powderer ginger, and mustard soed.

2 tablespoons celery soed (crushed).

1 tablespoon each of whole popper, cloves, cinnamon, and allspice.

Mix tho cucumber and onion and sprinkle alternato layers with salt, using three-fourths cup for wholo. Let stand over night. Put peppers into brine ovor night. Next morning drain vegetables and freshen for 1 to 2 hours in cloar water.

Put all whole spices into cheesecloth bag oxcept the celery seod and mustard seed, which are put in loose. Add spices to the vinegar and boil for 5 minutes. Drain tho vegetables well and pour tho hot spiced vinegur over them. Let stand 24 hours. Pack, distributing the pepper well and flattening some of the cucumber slices against tho fuce of each jur. Fill jars with same vinegar and paddle well to remove all bubbles. Garnish with strips of red pepper or pieces of spice. Process 12-ounce or pint jar for 15 minutes at $180^{\circ} \mathrm{F}$. 


\section{PICKLED ONIONS.}

Select small white onions and sort into two sizes, $\frac{1}{2}$ inch diameter in one and $\frac{3}{4}$ inch in other. Peel, cover with fresh water and let stand for 2 days, changing the water on second day. Wash well and put into brine for 4 days, changing brine at end of second day. Take out of brine and put into boiling water. Let stand for 10 minutes, then put into cold water for 2 hours. Drain, and pack into jars, putting in a few small red peppers, and garnishing with sprigs of mace. Fill jars to overflowing with spiced vinegar, made previously and allowed to stand for a few days with spice bags left in it. Process as for pickles.

\section{SPICED VINEGAR.}

$\frac{1}{2}$ gallon vinegar.

$1 \frac{1}{2}$ tablespaons celery seed. $\frac{1}{2}$ cup grated horse-radish.

1 cup sugar.
$1 \frac{1}{2}$ tablespoons mustard seed.

1 tablespoon salt.

1 tablespoon cinnamon.

Cloves, nutmeg, and grated onion may be added if desired.

\section{GREEN TOMATO PICKLE.}

1 gallon green tomatoes.

$\frac{1}{2}$ dozen large onions.

3 cups brown sugar.

$\frac{1}{2}$ lemon.

3 pods of red pepper.

3 cuips vinegar.

1 tablespoon whole black pepper.
1 tablespoon whole cloves.
1 tablespoon whole allspice.
1 tablespoon celery seed (crushed).
1 tablespoon mustard seed.
1 tablespoon ground mustard.

Slice the tomatoes and onions thin. Sprinkle over them $\frac{1}{2}$ cup of salt and let stand over night in a crock or enameled vessel. Tie the pepper, cloves, allspice, and celery seed in a cheesecloth bag. Slice the lemon and chop two pepper pods very fine. Drain the tomato and onion well. Add all seasoning except one pepper pod to the vinegar, then add the tomato and onion. Cook for $\frac{1}{2}$ hour, stirring gently at intervals to prevent burning. Remove spice bag to prevent darkening product. Pack in 10-ounce jar and garnish with slender strips of the red pepper, placing them vertically on the opposite sides of each jar. Process for 15 minutes.

Mary E. Creswell,

Ola Powell,

Assistants in Home Demonstration Work.

Approved:

BradFord KNApP,

Chief, Office of Extension Work, South. 
